\title{
Electrochemical performances of Asymmetric super capacitor fabricated by one-dimensional $\mathrm{CoMoO}_{4}$ nanostructure
}

\author{
Yunxuan Zhao, Fei Teng*, Zailun Liu, Qian Du, Jingjing Xu, Yiran Teng
}

Jiangsu Engineering and Technology Research Center of Environmental Cleaning Materials (ECM), Jiangsu Collaborative Innovation Center of Atmospheric Environment and Equipment Technology (AEET), Jiangsu Joint Laboratory of Atmospheric Pollution Control (APC), Jiangsu Key Laboratory of Atmospheric Environment Monitoring and Pollution Control (AEMPC), School of Environmental Science and Engineering, Nanjing University of Information Science \& Technology, China

* Corresponding author. Email: tfwd@ 163.com (F. Teng); Phone/fax: 86-25-58731090 


\begin{abstract}
We have prepared the $\mathrm{CoMoO}_{4}$ nanorods (NR) electrode with a specific capacitance $\left(89.5 \mathrm{~F} \mathrm{~g}^{-1}\right)$ at a current density of $1 \mathrm{~mA} \mathrm{~cm}^{-2}$. Moreover, the asymmetric supercapacitor (ASC) has been fabricated by using $\mathrm{CoMoO}_{4} \mathrm{NR}$ as positive electrode and activated carbon (AC) as negative electrode. At a power density of $80 \mathrm{mWcm}^{-3}$, the ASC can deliver an energy density of $0.226 \mathrm{mWh} \mathrm{cm}^{-3}$ in the voltage range of 0-1.6V. In addition, the $\mathrm{CoMoO}_{4}$ NR-based ASC device still remains a high energy density $(84.07 \%)$ after 5,000 cycles, demonstrating that one-dimensional nanostructures could be promising to achieve the high-energy-density materials.
\end{abstract}

Keywords: $\mathrm{CoMoO}_{4}$ nanorods; Energy density; Asymmetric supercapacitor (ASC) 


\section{Introduction}

To meet the increasing energy demand, incredible efforts have been made to develop the flexible energy storage and conversion devices with high energy and power density ${ }^{[1,2]}$. Amongst, supercapacitor (SC) has attracted considerable attention for the high power density and excellent safety ${ }^{[2,3]}$. Compared to fuel cells and renewable alternative batteries, the SCs have been widely used in hybrid electric vehicles, industry powergrids and military devices. ${ }^{[4,5]}$ However, the lower energy densities of presently existing SCs limit the actual applications. Thus, it still remains a big challenge to obtain a high-energy-density SC.

According to $\mathrm{E}=0.5 \mathrm{CV}^{2},{ }^{[6-8]}$ the energy density (E) value of $\mathrm{SC}$ can be improved by increasing the cell potential $(\mathrm{V})$ and specific capacitance $(\mathrm{C}) .{ }^{[9-12]}$ Herein, $\mathrm{V}$ value can be increased through the asymmetric configuration and $\mathrm{C}$ value can be increased by developing excellent electrode materials. In most recent years, ternary metal oxides have gained great interest because of their feasible oxidation state, high electrical conductivity and high electrochemical activity, e.g. $\mathrm{ZnCo}_{2} \mathrm{O}_{4},{ }^{[13,14]} \mathrm{Zn}_{2} \mathrm{SnO}_{4}$, ${ }^{[15]} \mathrm{NiCo}_{2} \mathrm{O}_{4},{ }^{[16-19]} \mathrm{NiMoO}_{4},{ }^{[20,21]} \mathrm{MnMoO}_{4},{ }^{[22]}$ and so on. Among, $\mathrm{CoMoO}_{4}$ has attracted particular attention due to its excellent electrochemical performances. ${ }^{[23,24]}$ Nevertheless, the poor conductivity of $\mathrm{CoMoO}_{4}$ still limit its application in SC and the flexible asymmetric supercapacitors (ASCs) built based on one-dimensional CoMoO4 nanostructure have not been studied extensively.

In this work, we develop flexible asymmetric supercapacitors (ASCs) by using $\mathrm{CoMoO}_{4} \mathrm{NR}$ and activated carbon (AC) as positive and negative electrodes, respectively. The as-fabricated ASC shows a high energy density of $0.2263 \mathrm{mWh} \mathrm{cm}^{-3}$ at a power density of $80 \mathrm{~mW} \mathrm{~cm}{ }^{-3}$, which is superior to many previously reported ASCs. Furthermore, the optimized ASC, with an output voltage of $1.6 \mathrm{~V}$, exhibits a 
remarkable rate capacitance and a good cycle stability $(84.07 \%$ of the initial energy density after 5,000 cycles). This work suggests that the high-energy-density capacitor can be developed by one-dimensional nanostructure and asymmetric configuration of electrodes. 


\section{Experimental}

\subsection{Sample preparation}

The $\mathrm{CoMoO}_{4} \mathrm{NRs}$ were synthesized by a simple hydrothermal method. In detail, $1.5 \mathrm{mmol} \mathrm{Co}\left(\mathrm{NO}_{3}\right)_{2} \cdot 6 \mathrm{H}_{2} \mathrm{O}$ was dissolved in $30 \mathrm{~mL}$ distilled water, then the solution was stirred at room temperature for $10 \mathrm{~min}$ by a magnetic stirrer. After $1.5 \mathrm{mmol}$ of $\mathrm{Na}_{2} \mathrm{MoO}_{4} \cdot 2 \mathrm{H}_{2} \mathrm{O}$ was added to the solution above, the mixture was stirred for $30 \mathrm{~min}$ to form a solution. Then, the solution was transferred to a 50-mL Teflon-lined autoclave and was heated at $150{ }^{\circ} \mathrm{C}$ for $5 \mathrm{~h}$. After the reaction completed, the sample was collected and washed with distilled water for several times and dried at $60{ }^{\circ} \mathrm{C}$ for $24 \mathrm{~h}$.

\subsection{Characterization}

The morphology of the sample was characterized by scanning electron microscope (SEM, Hitachi, SU-1510) using an accelerating voltage of $15 \mathrm{kV}$. The fine surface structure of the sample was characterized by high-resolution transmission electron microscopy (HRTEM, JEOL JEM-2100F) equipped an electron diffraction (ED) attachment with an acceleration voltage of $200 \mathrm{kV}$. The crystal phase of the sample was characterized by X-ray diffraction (XRD, Rigaku D/max-2550VB) with graphite monochromatized $\mathrm{Cu} \mathrm{K}_{\alpha}$ radiation $(\lambda=0.154 \mathrm{~nm})$. X-ray photoelectron spectroscopy (XPS) measurements were done on a VG ESCALAB MKII XPS system with $\mathrm{Mg} \mathrm{K} \mathrm{K}_{\alpha}$ source and a charge neutralizer. All the binding energies were referenced to the $\mathrm{C} 1 \mathrm{~s}$ peak at $284.8 \mathrm{eV}$ of the surface adventitious carbon. Nitrogen adsorption-desorption isotherms were obtained at $77 \mathrm{~K}$ using the Autosorb-iQ physicoadsorption apparatus (Quantachrome). Surface area was calculated by the Brunauer-Emmett-Teller (BET). 


\subsection{Electrochemical measurements}

All the electrochemical measurements were carried out on a CHI 660D electrochemical workstation. The working electrode consists of $80 \mathrm{wt} \%$ of $\mathrm{CoMoO}_{4}$ NR, $10 \mathrm{wt} \%$ of carbon black and $10 \mathrm{wt} \%$ of polyvinylidene fluoride (PVDF). The powders were mixed with $0.3 \mathrm{~mL}$ of $\mathrm{N}$-methylpyrrolidinone (NMP) to form a uniform slurry. The resulting slurry was coated onto carbon fibre $(\mathrm{CF})$ and dried at $60{ }^{\circ} \mathrm{C}$ overnight. A Pt wire and a standard saturated calomel electrode (SCE) were used as a counter electrode and a reference electrode, respectively. A standard three-electrode cell was used, in which $1 \mathrm{M} \mathrm{KOH}$ aqueous solution was used as the electrolyte solution.

Cyclic voltammetry (CV) and chronopotentiometry (CP) were conducted in a potential range of $-0.1-0.4 \mathrm{~V}$ ( $v s$. S.C.E). Electrochemical impedance spectroscopy (EIS) was performed from $0.1 \mathrm{~Hz}$ to $100 \mathrm{KHz}$ at an alternating current voltage amplitude of $5 \mathrm{mV}$.

\subsection{Fabrication of asymmetric supercapacitor (ASC)}

Typically, $80 \mathrm{wt} \%$ active carbon (AC) was mixed with $20 \mathrm{wt} \%$ PVDF to form a uniform slurry, and then the slurry was coated onto carbon fibre (CF). The AC@CF negative electrode was combined with the $\mathrm{CoMoO}_{4} @ \mathrm{CF}$ positive electrode to assemble the full ASC cell, with $1 \mathrm{M} \mathrm{KOH}$ as the electrolyte. The mass ratio of positive and negative electrodes is based on the charge balance theory $\left(\mathrm{Q}^{+}=\mathrm{Q}^{-}\right)$. The specific capacitance, energy and power densities of the ASC were all calculated on base of the total mass of both negative and positive electrodes. 


\section{Results and Discussion}

\subsection{Characterization of $\mathrm{CoMoO}_{4} \mathrm{NR}$}
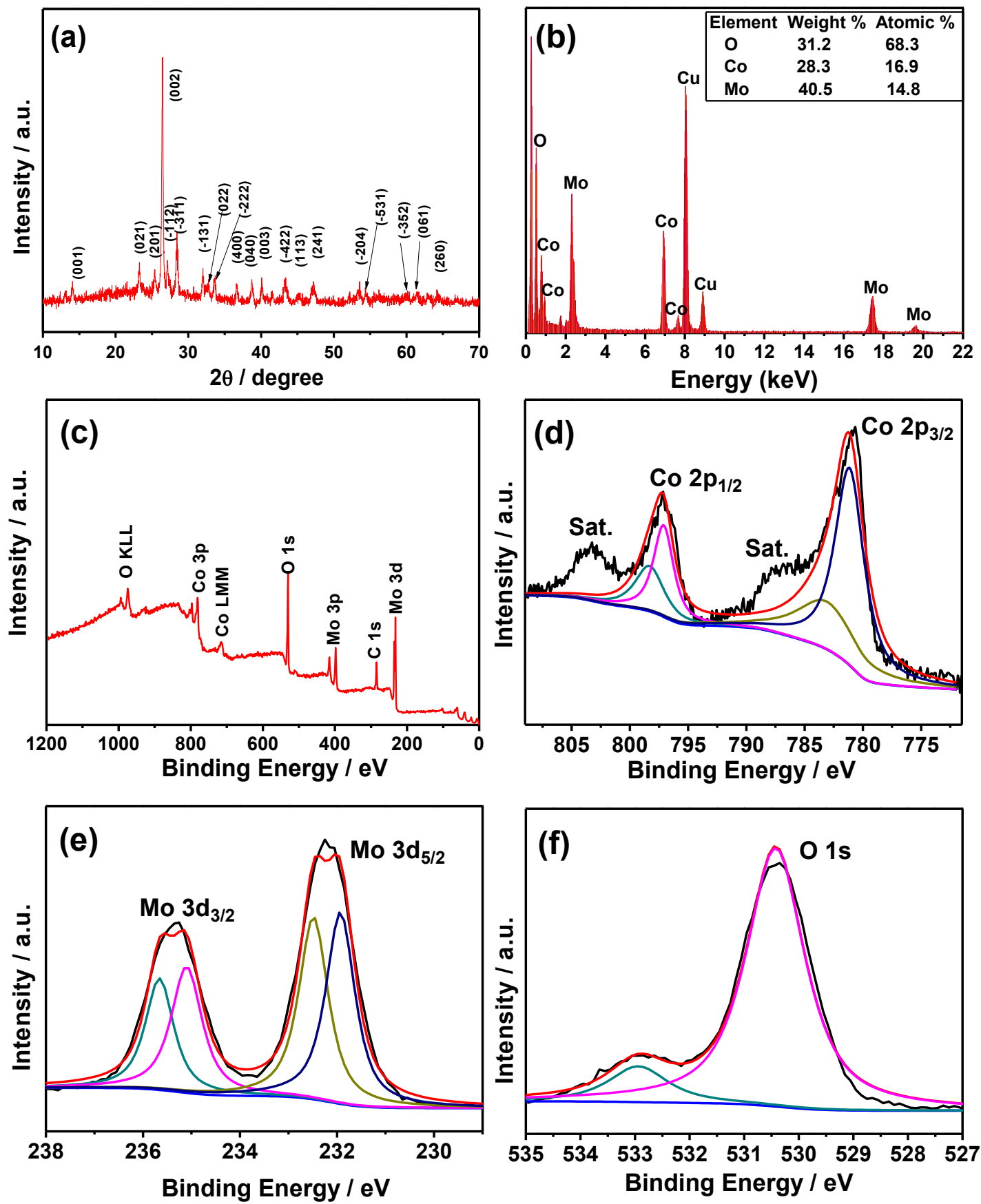

Fig. $1 \mathrm{CoMoO}_{4}$ nanorods (NR): (a) XRD patterns; (b) Energy-dispersive X-ray spectrum (EDS) (the inset of the element composition); (c) Survey X-ray photoelectron spectroscopy (XPS) spectra; (d) Co 2p XPS; (e) Mo 3d XPS; (f) O 1s 
XPS spectra

$\mathrm{CoMoO}_{4} \mathrm{NR}$ can be easily prepared through the simple hydrothermal method. The X-ray diffraction (XRD) analysis is used to demonstrate the crystal phase of the sample. As shown in Fig. 1a, all diffraction peaks of the sample can be assigned to monoclinic $\mathrm{CoMoO}_{4}$ (JCPDS file no. 21-0868). The energy-dispersive X-ray spectroscopy (EDS) of $\mathrm{CoMoO}_{4} \mathrm{NR}$ confirms that the atom ratio of $\mathrm{Co}: \mathrm{Mo}: \mathrm{O}$ was approximately 1:1:4, in agreement with that of $\mathrm{CoMoO}_{4}$ (Fig. 1b).

Besides, we resort to X-ray photoelectron spectroscopy (XPS) measurements to insight the chemical states and elemental composition of the sample. The typical survey XPS spectra (Fig. 1c) reveal the coexistence of Mo, Co, $\mathrm{C}$ and $\mathrm{O}$ elements in both samples. The Co 2p XPS spectra (Fig. 1d) of $\mathrm{CoMoO}_{4} \mathrm{NR}$ presents two major peaks at $780.2 \mathrm{eV}$ and $795.3 \mathrm{eV}$ with a spinning energy of $15 \mathrm{eV}$, corresponding to the Co $2 p_{3 / 2}$ and Co $2 p_{1 / 2}$, respectively. ${ }^{[25-27]}$ In the case of $\mathrm{CoMoO}_{4} \mathrm{NR}$, the peaks of Co $2 \mathrm{p}_{3 / 2}$ and Co $2 \mathrm{p}_{1 / 2}$ locate at $780.8 \mathrm{eV}$ and $796.7 \mathrm{eV}$, respectively; which are in good agreement with the reported results. ${ }^{[28,29]}$ From the Mo 3d XPS spectra (Fig. 1e), we notice two peaks at about $232.15 \mathrm{eV}$ and $235.25 \mathrm{eV}$, corresponding to Mo $3 \mathrm{~d}_{5 / 2}$ and Mo $3 \mathrm{~d}_{3 / 2}$, respectively. ${ }^{[30-32]}$ The $\mathrm{O} 1 \mathrm{~s}$ peaks at $529.98 \mathrm{eV}$ and $530.3 \mathrm{eV}$ indicate the existence of $\mathrm{O}^{2-}$ species (Fig. 1f). ${ }^{[33]}$

Furthermore, the sample has been characterized by scanning electron microscopy (SEM) and high-resolution transmission microscopy (HRTEM) (Fig. 2). Fig. 2a and $2 \mathrm{~b}$ show that the $\mathrm{CoMoO}_{4}$ NRs are 1-2 $\mu \mathrm{m}$ long and their average diameters are about $200 \mathrm{~nm}$. The interplanar spacing is determined to be $0.277 \mathrm{~nm}$, corresponding to the (-131) planes of $\mathrm{CoMoO}_{4}$ (Fig. 2c), indicating the nanorods grow preferentially along [131] direction. The single-crystalline nature of the $\mathrm{CoMoO}_{4} \mathrm{NR}$ can be revealed by 
the selected area electron diffraction (SAED) patterns (Fig. 2d) and the clear diffraction spots can be identified as the (-131) and (002) planes of the $\mathrm{CoMoO}_{4}$.
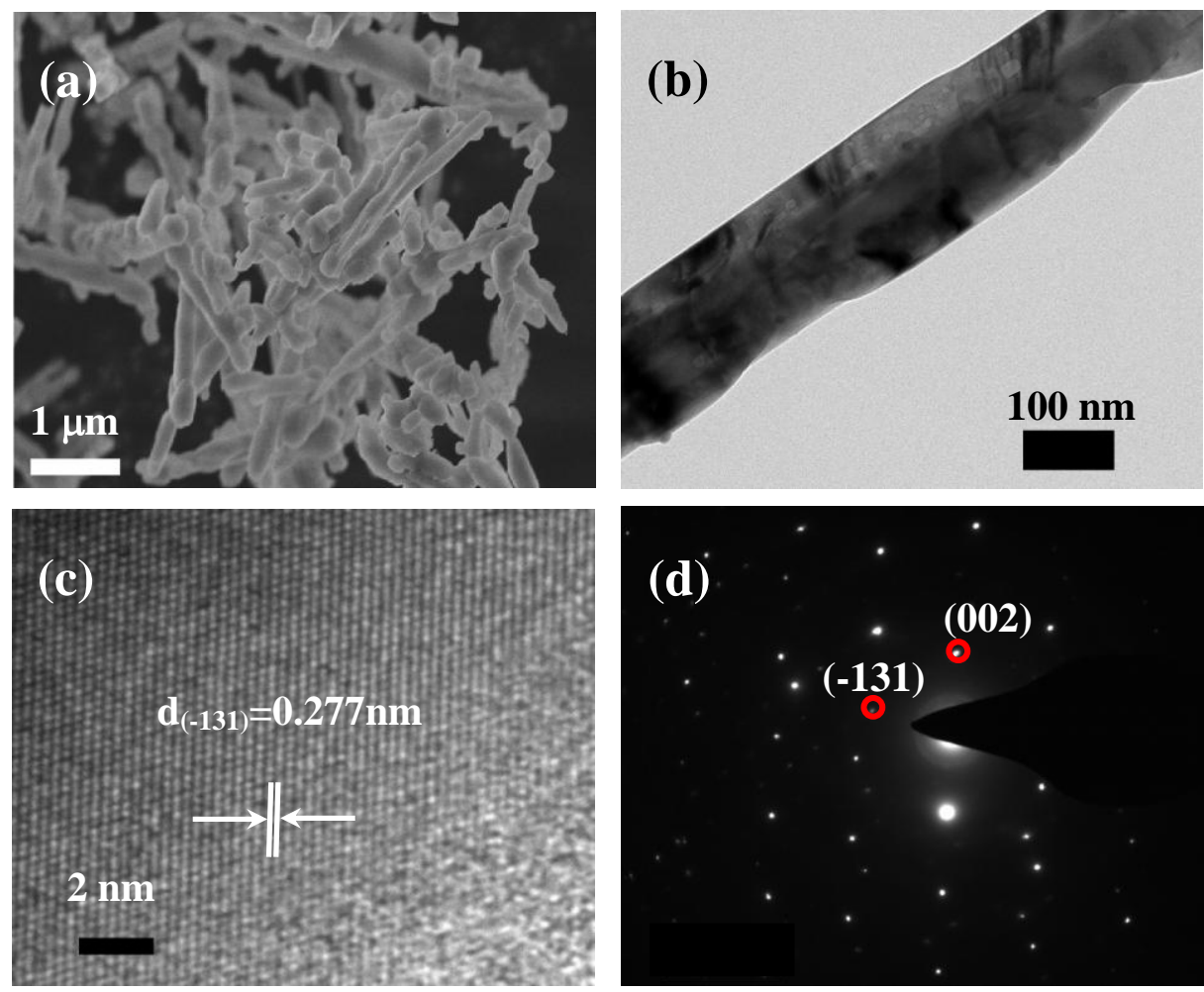

Fig. 2 SEM, HRTEM images and electron diffraction patterns (ED) of $\mathrm{CoMoO}_{4} \mathrm{NR}$ :

(a) SEM image; (b) TEM image; (c) Lattice fringe images; (d) ED patterns

\section{2. $\mathrm{CoMoO}_{4} \mathrm{NR}$ electrode}

The electrochemical properties of $\mathrm{CoMoO}_{4} \mathrm{NR}$ electrodes are investigated by the electrochemical impedance spectroscopy (EIS), cyclic voltammetry (CV) and chronopotentiometry (CP). Herein, $\mathrm{CV}$ s are measured in $1 \mathrm{M} \mathrm{KOH}$ aqueous solution in a three-electrode system. Fig. 3a shows the CV curves of $\mathrm{CoMoO}_{4} \mathrm{NR}$ at different scanning rates $\left(5-100 \mathrm{mVs}^{-1}\right)$. A pair of redox peaks can be observed in each $\mathrm{CV}$ curve, suggesting a typical pseudo-capacitive behavior. In the alkaline electrolyte solution, such Faradic redox reactions can be attributed to the mutual conversion between $\mathrm{Co}^{2+}$ 
and $\mathrm{Co}^{3+} \cdot{ }^{[22,34]}$ It can be seen that the peak current increases, but the shape of the $\mathrm{CV}$ curves is not influenced by increasing the scanning rate, which suggests an improved electron-transfer efficiency in the host material. Besides, as the scanning rate increases, the anodic peaks shift to higher potential while the cathodic peaks shift to lower potential due to greater ohmic overpotential; but the CV curves still showed symmetrical redox shape, indicating stable and fast redox reaction.
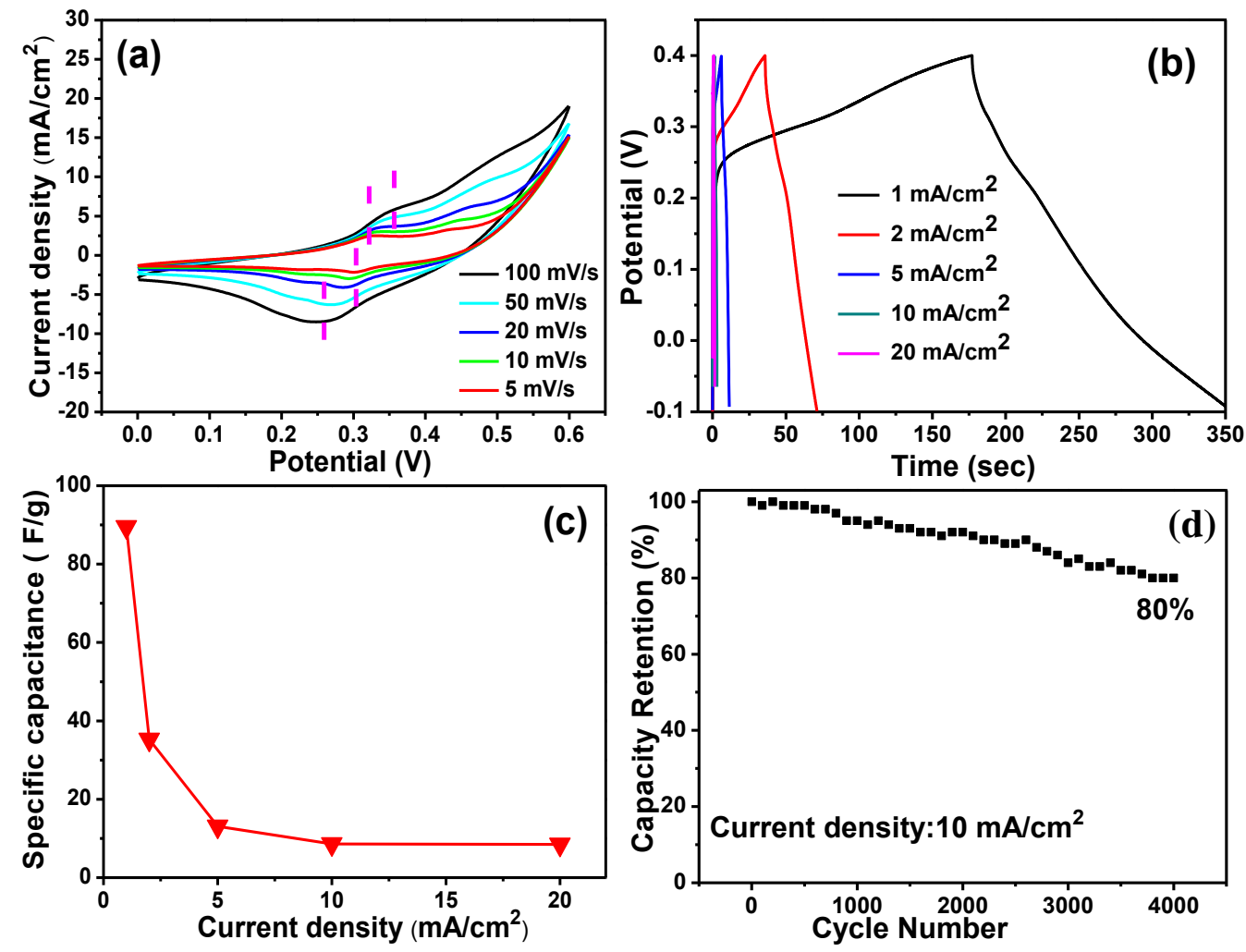

Fig. 3 Electrochemical properties of $\mathrm{CoMoO}_{4} \mathrm{NR}$ : (a) Cyclic voltammetry (CV) curves; (b) Galvanostatic charge-discharge curves; (c) Specific capacitances at different current densities; (d) Cycle stability

Fig. $3 \mathrm{~b}$ shows the galvanostatic charge-discharge curves at the current densities from 1 to $10 \mathrm{~mA} \mathrm{~cm}{ }^{-2}$. The nonlinear charge/discharge profile could be attributed to the pseudo-capacitive behavior. ${ }^{[35,36]}$ The specific capacitance of electrode is calculated according to the following equation:

$$
\mathrm{C}=I \Delta t / m \Delta \mathrm{V}
$$


where $I$ is the discharge current, $\Delta t$ is the discharge time, $\Delta \mathrm{V}$ is the voltage range, and $m$ is the mass of active material. Fig. 3c shows the calculated discharge capacitances of $\mathrm{CoMoO}_{4} \mathrm{NR}$ at various current densities. Specifically, the discharge capacitances are $89.5,35.26,13.18 .6$ and $8.5 \mathrm{~F} \mathrm{~g}^{-1}$ at the current densities of $1,2,5,10$ and $20 \mathrm{~mA}$ $\mathrm{cm}^{-2}$, respectively. The discharge capacitance significantly decreases with the increase of discharge current density, but the discharge capacitance did not decrease with the current densities of 10 and $20 \mathrm{~mA} \mathrm{~cm}^{-2}$. Further, Fig. 3d presents the cycle stability of $\mathrm{CoMoO}_{4} \mathrm{NR}$ electrodes at $10 \mathrm{~mA} \mathrm{~cm}^{-2}$ for 4000 cycles. After 4000 cycles, $80 \%$ of capacitance is remained for $\mathrm{CoMoO}_{4} \mathrm{NR}$, indicating an excellent electrochemical stability. The result suggests that $\mathrm{CoMoO}_{4}$ NR can be used as an outstanding electrode material. To further understand the electrochemical performances of the electrode, electrochemical impedance spectroscopy (EIS) analysis is carried out, as shown in Fig. 4a. The measured impedance data are fitted and further analyzed by an equivalent electrical circuit (the inset of Fig. 4a), which consists of electrolyte solution resistance $\left(\mathrm{R}_{\mathrm{s}}\right)$, Warburg impedance $(\mathrm{W})$, charge-transfer impedance $\left(\mathrm{R}_{\mathrm{ct}}\right)$ and a constant phase element (CPE). The $\mathrm{CoMoO}_{4} \mathrm{NR}$ electrode has a small $\mathrm{R}_{\mathrm{ct}}(2.84 \Omega)$, indicating a high electrochemical conductivity. Their excellent electrochemical performances could be attributed to the 1-D nanostructure. ${ }^{[24,36]}$ On one hand, the BET area of $\mathrm{CoMoO}_{4} \mathrm{NR}$ is $10.8 \mathrm{~m}^{2} \mathrm{~g}^{-1}$ (Fig. 4b). It is well known that the high BET area could increase electrolyte/electrode contact area and provide more active sites, which can lead to a high specific capacitance. ${ }^{[14]}$ On the other hand, the $\mathrm{CoMoO}_{4}$ nanorods will be beneficial to shorten the diffusion paths for both electrons and ions due to the specific one-dimensional nanostructure, thus leading to fast electron transport and ion diffusion rates during charge-discharge processes. ${ }^{[34]}$ The results verify that $\mathrm{CoMoO}_{4} \mathrm{NR}$ could be a promising candidate for supercapacitor material. 

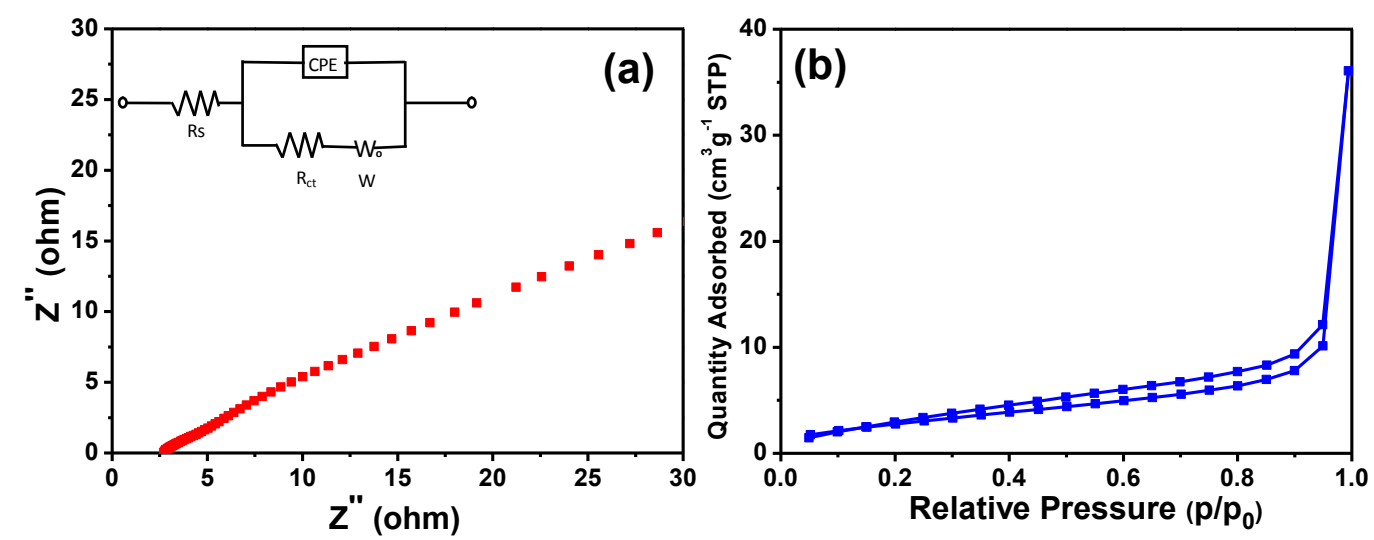

Fig. 4 (a) Nyquist plot (the inset of the equivalent electrical circuit) and (b) Nitrogen sorption isotherms of $\mathrm{CoMoO}_{4} \mathrm{NRs}$.

\subsection{ASC device}

To further evaluate the practical applications of $\mathrm{CoMoO}_{4} \mathrm{NR}$, the ASC devices are assembled by using $\mathrm{CoMoO}_{4} \mathrm{NR}$ /carbon fiber as the cathode, $\mathrm{AC} /$ carbon fiber as the anode, $1 \mathrm{M} \mathrm{KOH}$ as the electrolyte solution, and filter paper as the separator. The ASC configure is presented in Fig. 5a. Fig. 5b shows the CV curves of the optimized ASC device fabricated by $\mathrm{CoMoO}_{4} \mathrm{NR}$ at different scanning rates $(5,10,20,50$ and $\left.100 \mathrm{mVs}^{-1}\right)$. The operating cell voltage $(1.6 \mathrm{~V})$ is much higher than the conventional active carbon (AC)-based symmetric supercapacitors in aqueous electrolytes (0.8-1.0V), which makes it possible to achieve a high energy density. Moreover, it should be worth noting that water splitting can be avoided due to the existence of an overpotential. Fig. 5c presents the galvanostatic charge/discharge curves at different current densities $\left(1.5,3,6,12\right.$ and $\left.24 \mathrm{~mA} \mathrm{~cm}^{-3}\right)$ for the $\mathrm{CoMoO}_{4}$ NR-based ASC device and Fig. 6 shows the CV curves of positive and negative electrodes, which are tested in a three-electrode cell. Clearly, the nonlinear charge/discharge curves could indicate a typical pseudo-capacitive behavior in $\mathrm{CoMoO}_{4} \mathrm{NR}$-based ASC device. From the CV curve of the, however, the CV curve of AC@CF electrode presents an 
electrochemical double layer behavior (capacitor type). The as-fabricated ASCs can make full use of both capacitive behaviors to enhance the operation voltage window.

According to these results above, the Ragone plots of ASCs describe the relationship between volumetric energy density $\left(E=\left(C \Delta \mathrm{U}^{2} / 2\right)\right)$ and volumetric power density $(\mathrm{P}=(\mathrm{E} / \mathrm{t}))($ Fig. 7a). Notably, our ASC displays a high energy density of $0.226 \mathrm{mWh}$ $\mathrm{cm}^{-3}$ at a power density of $80 \mathrm{~mW} \mathrm{~cm}$. Even at a high power density of $640 \mathrm{~mW}$ $\mathrm{cm}^{-3}$, the ASC still maintains $0.083 \mathrm{mWh} \mathrm{cm}^{-3}$ much superior to those of electric double-layer capacitors. ${ }^{[11,24]}$ More interestingly, its high energy density is advantageous over the previously reported systems, for example, graphene-based SC $\left(0.06 \mathrm{mWh} \mathrm{cm}^{-3}\right.$ at $\left.0.2 \mathrm{~W} \mathrm{~cm}^{-3}, \mathrm{PVA} / \mathrm{H}_{3} \mathrm{PO}_{4}\right),{ }^{[24]}$ TiN-based $\mathrm{SC}\left(0.05 \mathrm{mWh} \mathrm{cm}^{-3}\right.$ at $0.1 \mathrm{~W} \mathrm{~cm}-3, \mathrm{PVA} / \mathrm{KOH}),{ }^{[11]} \mathrm{H}^{-\mathrm{TiO}_{2}} @ \mathrm{MnO}_{2} / / \mathrm{H}-\mathrm{TiO}_{2} @ \mathrm{C} \mathrm{ASC}\left(0.3 \mathrm{mWh} \mathrm{cm}{ }^{-3}\right.$ at 0.2 $\left.\mathrm{W} \mathrm{cm}{ }^{-3}, 5 \mathrm{M} \mathrm{LiCl}\right)^{[36,37]}$ and $\mathrm{MnO}_{2} @ \mathrm{CoMoO}_{4} @ \mathrm{Ni}$ ASC $\left(2.26 \mathrm{mWh} \mathrm{cm}{ }^{-3}\right.$ at 4 $\mathrm{mW} / \mathrm{cm}^{3} \cdot{ }^{[38]}$

Moreover, Fig. 7b exhibits the cycling performance of the ASC device. After 5000 cycles, it can be clearly seen that the discharge capacitance still remains $84.07 \%$ of initial specific capacitance, which suggesting the excellent long-term electrochemical stability of ASC device. To conclude, a high energy can be reached for the $\mathrm{CoMoO}_{4} \mathrm{NR}$-based ASC, which is promising for practical application. 

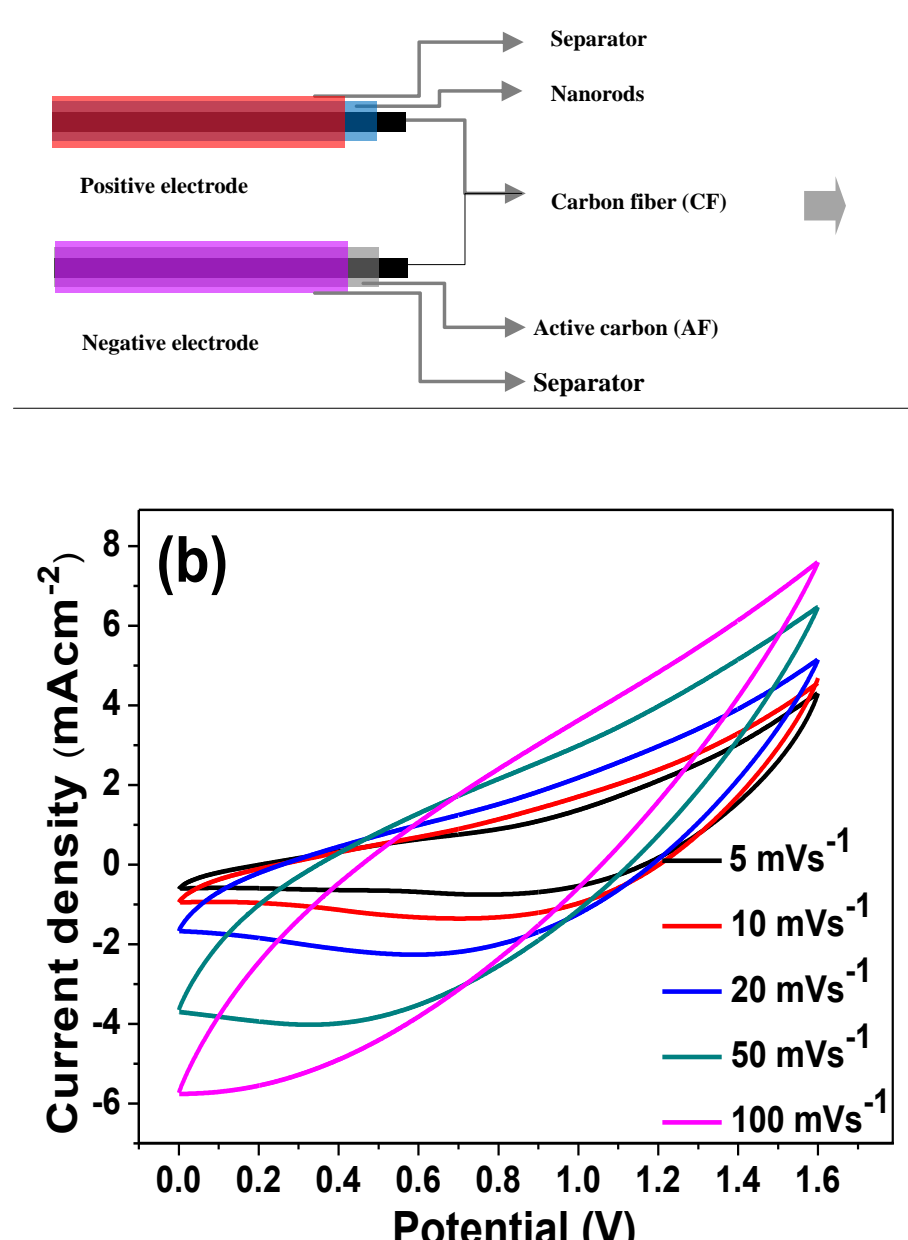

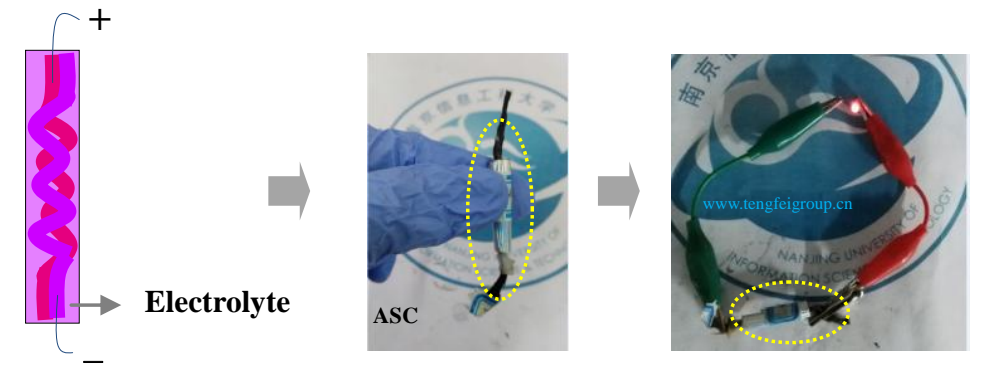

(a)

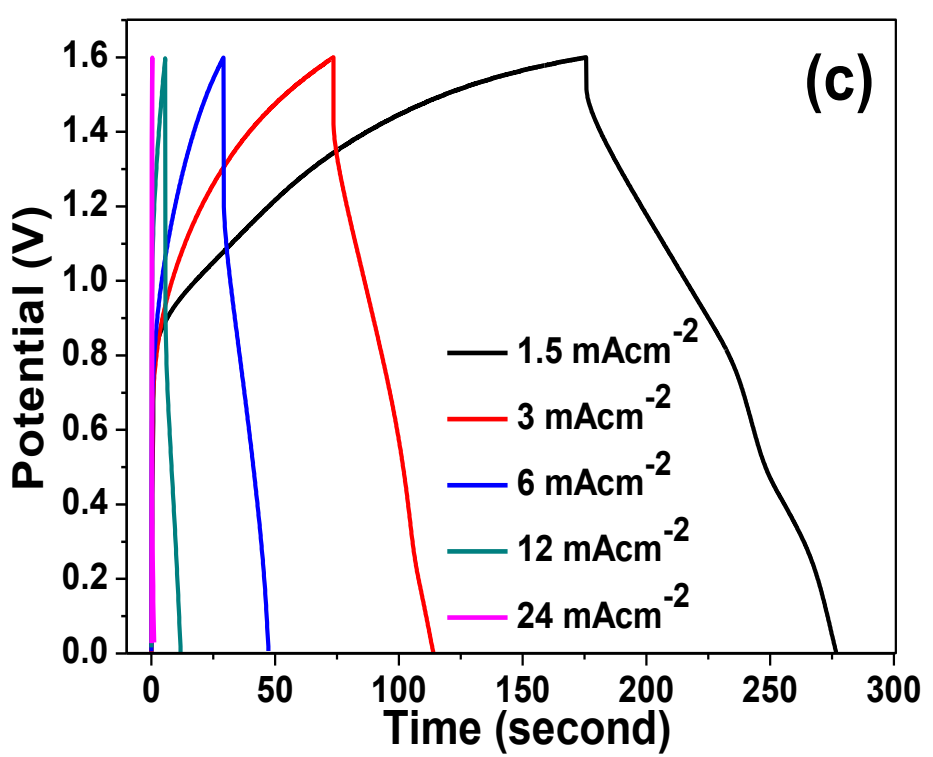

Fig. 5 Flexible asymmetric supercapacitors (ASC): (a) Schematic configuration of ASC; (b) CV curves with a voltage window of 0-1.6 V; (c)

Change-discharge curve 


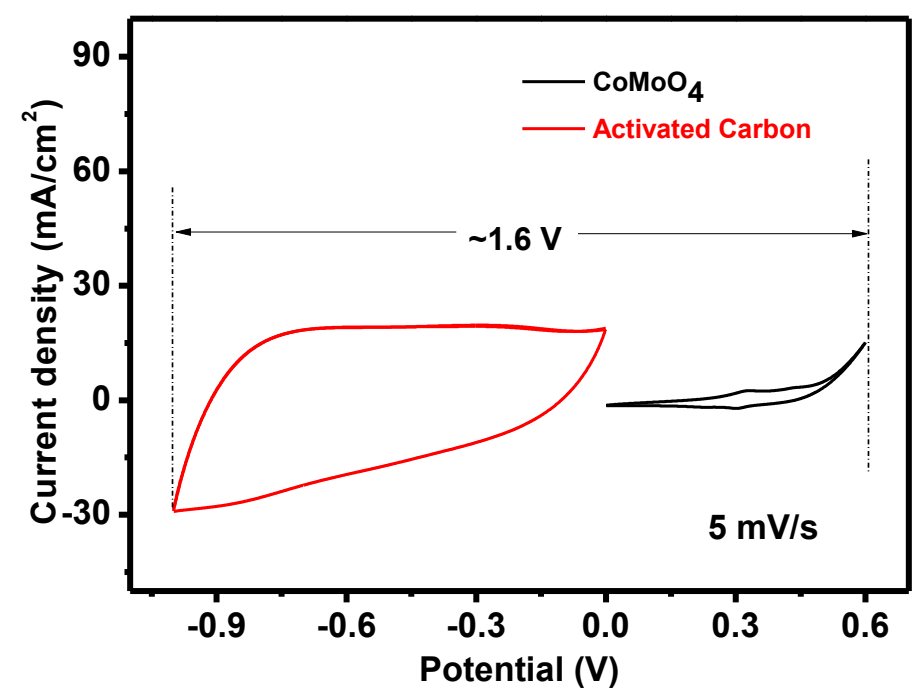

Fig. 6 Comparative $\mathrm{CV}$ curves of the $\mathrm{CoMoO}_{4} @$ carbon fibre $(\mathrm{CF})$ electrode and activated carbon (AC) electrode (three-electrode cell, vs. SCE)
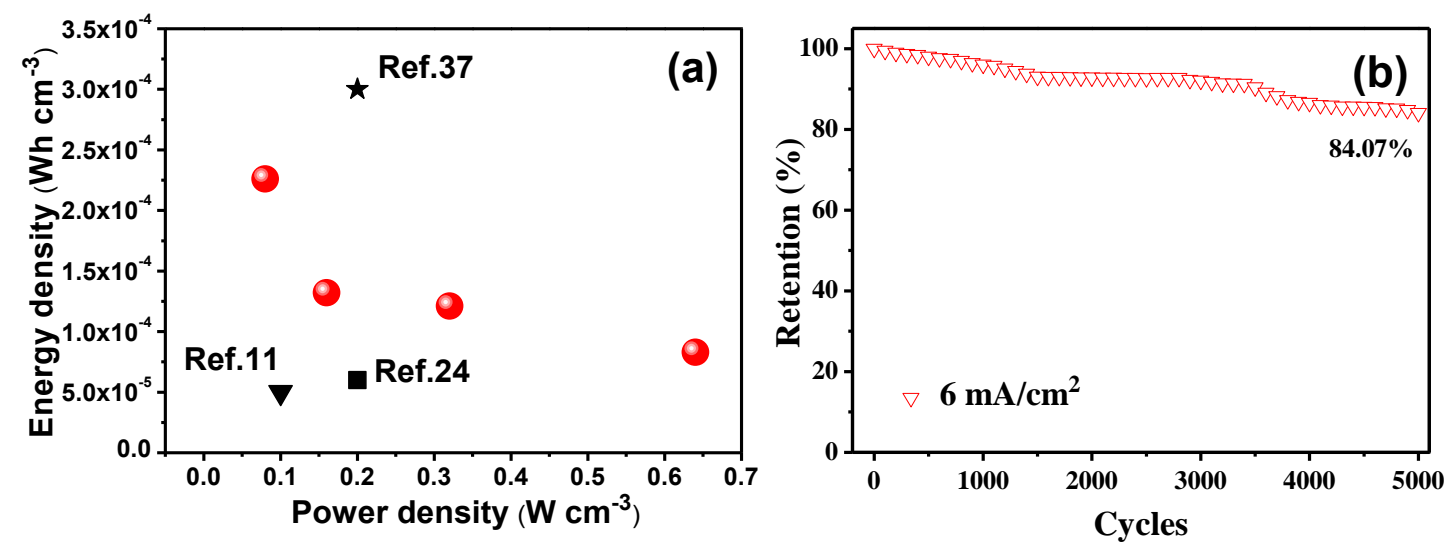

Fig. 7 Ragone plots (a) and cycling stability (b) of the $\mathrm{CoMoO}_{4}$ NR-based ASC

\section{Conclusions}

$\mathrm{CoMoO}_{4} \mathrm{NR}$-based ASC delivers a high energy density of $0.226 \mathrm{mWh} \mathrm{cm}^{-3}$ at a power density of $80 \mathrm{~mW} \mathrm{~cm}^{-3}$, which has been mainly ascribed to the specific one-dimensional nanostructure that leads to the fast electron transport and ion diffusion rates. Our results demonstrate that a high-energy-density supercapacitor can be achieved by using 1-D nanostructure and the asymmetric configuration. 


\section{Acknowledgements}

This work is financially supported by National Science Foundation of China (21377060), Scientific Research Foundation for the Returned Overseas Chinese Scholars of State Education Ministry (20121707), Six Talent Climax Foundation of Jiangsu (20100292), the Key Project of Environmental Protection Program of Jiangsu (2013005), Jiangsu Science Foundation of China (BK2012862, BK2012464), “333” Outstanding Youth Scientist Foundation of Jiangsu (20112015), the Project Funded by the Science and Technology Infrastructure Program of Jiangsu (BM201380277), and A Project Funded by the Priority Academic Program Development of Jiangsu Higher Education Institutions (PAPD) sponsored by SRF for ROCS, SEM (2013S002).

\section{References}

[1] J. R. Miller, P. Simon, Science, 321 (2008) 651-652.

[2] P. Simon, Y. Gogotsi, Nat. Mater., 7 (2008) 845-854.

[3] H. Wang, H. S. Casalongue, Y. Liang, H. Dai, J. Am. Chem. Soc., 132 (2010) $7472-7477$

[4] G. Yu, L. Hu, M. Vosgueritchian, H. Wang, X. Xie, J. R. McDonough, X. Cui, Y. Cui, Z. Bao, Nano Lett., 11 (2011) 2905-2911.

[5] N. Yu, H. Yin, W. Zhang, Y. Liu, Z. Tang, M. Zhu, Adv. Energy. Mater., 6 (2016), 201501458

[6] H. Tang, J. Wang, H. Yin, H. Zhao, D. Wang, Z. Tang, Adv. Mater., 6 (2015) 
1117-1123.

[7] J.-H. Sung, S.-J. Kim, K.-H. Lee, J. Power Sources, 124 (2003) 343-350.

[8] K. Chau, Y. Wong, C. Chan, Energy Convers. Manage., 40 (1999) 1021-1039.

[9] J. Yan, Z. Fan, W. Sun, G. Ning, T. Wei, Q. Zhang, R. Zhang, L. Zhi, F. Wei, Adv. Funct. Mater., 22 (2012) 2632-2641.

[10] J. Xu, Q. Wang, X. Wang, Q. Xiang, B. Liang, D. Chen, G. Shen, ACS nano, 7 (2013) 5453-5462.

[11] X. Lu, G. Wang, T. Zhai, M. Yu, S. Xie, Y. Ling, C. Liang, Y. Tong, Y. Li, Nano Lett., 12 (2012) 5376-5381.

[12] M. Yu, Y. Zeng, Y. Han, X. Cheng, W. Zhao, C. Liang, Y. Tong, H. Tang, X. Lu, Adv. Funct. Mater., 5 (2015) 56-67.

[13] K. Karthikeyan, D. Kalpana, N. Renganathan, Ionics , 15 (2009) 107-110.

[14] B. Liu, B. Liu, Q. Wang, X. Wang, Q. Xiang, D. Chen, G. Shen, ACS Appl. Mater. Inter., 5 (2013) 10011-10017.

[15] L. Bao, J. Zang, X. Li, Nano Lett., 11 (2011) 1215-1220.

[16] C. Yuan, J. Li, L. Hou, X. Zhang, L. Shen, X. W. D. Lou, Adv. Funct. Mater, 22 (2012) 4592-4597.

[17] L. Huang, D. Chen, Y. Ding, S. Feng, Z. L. Wang, M. Liu, Nano Lett., 13 (2013) $3135-3139$

[18] G. Zhang, X. W. D. Lou, Sci. Rep., 3 (2013) 77-80.

[19] Q. Wang, X. Wang, J. Xu, X. Ouyang, X. Hou, D. Chen, R. Wang, G. Shen, Nano Energy, 8 (2014) 44-51.

[20] M.-C. Liu, L.-B. Kong, C. Lu, X.-J. Ma, X.-M. Li, Y.-C. Luo, L. Kang, J. Mater. Chem. A, 1 (2013) 1380-1387.

[21] B. Senthilkumar, K. V. Sankar, R. K. Selvan, M. Danielle, M. Manickam, RSC 
Adv., 3 (2013), 352-357.

[22] L.-Q. Mai, F. Yang, Y.-L. Zhao, X. Xu, L. Xu, Y.-Z. Luo, Nat. Commun., 2 (2011) 381.

[23] X. Yu, B. Lu, Z. Xu, Adv. Mater., 26 (2014) 1044-1051.

[24] G.K. Veerasubramani, K. Krishnamoorthy, S.J. Kim RSC Adv., 5 (2015) $16319-16327$.

[25] Z. Wang, L. Pan, H. Hu, S. Zhao, CrystEngComm, 12 (2010) 1899-1904.

[26] C. Loussot, P. Afanasiev, M. Vrinat, H. Jobic, P. Leverd, Chem. Mater, 18 (2006) $5659-5668$.

[27] J. Xiao, X. Zeng, W. Chen, F. Xiao, S. Wang, Chem. Commun., 49 (2013) 11734-11736.

[28] J. Xu, P. Gao, T. Zhao, Energ. Environ. Sci., 5 (2012) 5333-5339.

[29] J. Xiao, L. Wan, S. Yang, F. Xiao, S. Wang, Nano Lett., 14 (2014) 831-838.

[30] M. Zhang, C. Shao, J. Mu, Z. Zhang, Z. Guo, P. Zhang, Y. Liu, CrystEngComm, 14 (2012) 605-612.

[31] Z. Li, X. Chen, Z.-L. Xue, Sci. China Chem., 56 (2013) 443-450.

[32] H. Tang, J. Wang, H. Yin, H. Zhao, D. Wang, Z. Tang, Adv. Mater., 27 (2015) $1117-1123$

[33] M. Yu, W. Wang, C. Li, T. Zhai, X. Lu, Y. Tong, NPG Asia Mater., 6 (2014) e129.

[34] S. Peng, L. Li, H. B. Wu, S. Madhavi, X. W. D. Lou, Adv. Energy Mater, 5 (2015) 1401172.

[35] R. Rakhi, W. Chen, D. Cha, H. Alshareef, Nano Lett., 12 (2012) 2559-2567.

[36] L. Li, S. Peng, H. B. Wu, L. Yu, S. Madhavi and X. W. D. Lou, Adv. Energy Mater., 5 (2015) 1500753. 
[37] X. Lu, M. Yu, G. Wang, T. Zhai, S. Xie, Y. Ling, Y. Tong and Y. Li, Adv. Mater, 25 (2013) 267-272.

[38] Z. Liu, Z. Zhao, F.Teng, C. Chang, Y. Zhao, Y. Yang, W. Yao, Y. Zhu, Y. Fan, RSC Adv., 6 (2016) 46508-46515. 


\section{Graphic Abstract}
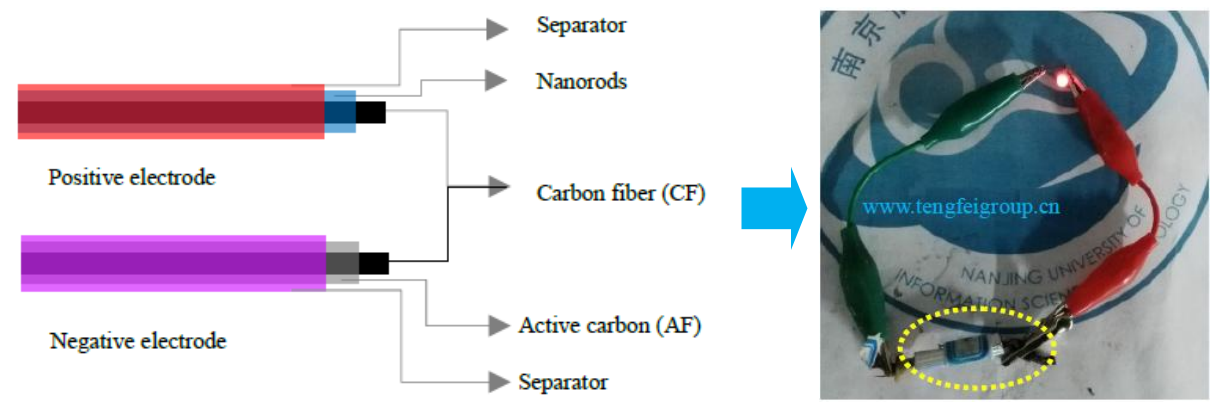

A flexible asymmetric super capacitor is fabricated by $\mathrm{CoMoO}_{4}$ nanorods. 